\title{
Saudi Teachers' Knowledge and Practices Related to Management of Students with Epilepsy
}

\author{
YOUSSEF ALI MOHAMAD AL-QAHTANI, M.D. ${ }^{\mathbf{1}}$; LUBNA HADDAJ AL-RUWAILI, M.B.B.S. ${ }^{\mathbf{2}}$; \\ ASMA SAEED N. AL-RUWAILI, M.B.B.S. ${ }^{2}$; WAFA DAIFALLAH AL-SHEHRI, M.B.B.S. ${ }^{\mathbf{B}}$; \\ YARA MOFARAH ASSIRI, M.B.B.S. ${ }^{\mathbf{3}}$; SALHA ALI ASERY, M.B.B.S. ${ }^{\mathbf{4}}$ and OSSAMA A. MOSTAFA, Dr.Ph. ${ }^{\mathbf{5}}$ \\ The Department of Pediatrics, Child Health, College of Medicine, King Khalid University, Abha ${ }^{1}$, \\ Medical student, College of Medicine, Northern Border University, Arar ${ }^{2}$ and King Khalid University, Abha ${ }^{3}$ \\ Pediatrics Resident, Abha Maternity \& Children's Hospital, Abha 4 and The Department of Family \& Community Medicine, \\ College of Medicine, King Khalid University, Abha ${ }^{5}$, Kingdom of Saudi Arabia
}

\begin{abstract}
Background: To assess teachers' knowledge and practice regarding management of epilepsy among schoolchildren.

Aim of Study: This study aimed to assess teachers' knowledge and their practices toward epileptic students in Arar City, northern Region of Saudi Arabia.

Subjects and Methods: A cross-sectional study was conducted in Arar City, at the Northern Region of Saudi Arabia. It included 404 school teachers (320 males and 84 females). A questionnaire testing teacher's knowledge and practice regarding management of students with epilepsy was constructed and used for data collection.

Results: Almost all participants (99\%) knew what epilepsy is, while only $39.4 \%$ knew that epilepsy is not contagious Only $46.5 \%$ knew causes of epilepsy, while only $30.4 \%$ denied the relation between epilepsy and evil eyes, and $50.5 \%$ correctly responded to questions related to role of certain types of food as triggering factors related to epileptic seizures. Most participants $(83.4 \%)$ correctly stated the relation between epilepsy and increased brain electric charges, while only $44.3 \%$ stated the early symptoms/signs of an imminent epileptic fit. Only $15.6 \%$ of participants denied that epilepsy does not affect child's intelligence, $67.3 \%$ knew complications of epilepsy, while $38.9 \%$ knew treatment of epilepsy. Participants' mean total knowledge score (out of 10) was 5.15 \pm 1.32 . Relatives and friends constitute the main source of teachers' knowledge about epilepsy $(49.1 \%)$, followed by internet $(44.1 \%)$ and lastly mass media $(4.9 \%)$, and books $(1.9 \%)$. $75.5 \%$ of participant teachers witnessed epileptic schoolchildren while in seizure. Their practices were mainly to call an ambulance $(72 \%)$, remove any dangerous objects around the victim $(69.1 \%)$, put a soft object between his teeth $(68.6 \%)$ ensure good ventilation (63.4\%) and pull his tongue out $(50.5 \%)$. Participants' mean total practice score (out of 10 ) was $4.85 \pm 1.28$. Mean teachers' knowledge and practice scores were highest among those aged $>50$ years $(5.34 \pm 1.75$ and
\end{abstract}

Correspondence to: Dr. Youssef Ali Mohamad Al-Qahtani, The Department of Pediatrics, Child Health, College of Medicine, King Khalid University, Abha, Kingdom of Saudi Arabia
$5.20 \pm 1.63$, respectively). However, differences were statistically significantly only regarding practice scores $(p<0.001)$. Female teachers' knowledge and practice scores were higher than those of male teachers, with statistically significant difference only regarding practice scores $(p=0.003)$. Teachers' knowledge and practice scores were highest among those with Master Degree, but with significant difference only regarding their practice $(p=0.029)$. Moreover, knowledge and practice scores did not differ significantly according to teachers' type of school.

Conclusions: School teachers in Northern Saudi Arabia have relatively poor knowledge and practices about management of epilepsy among students. It is recommended to provide teachers with information about handling seizures in the educational setting through development and implementation of epilepsy education programs.

Key Words: Knowledge - Practice - School teachers - Epilepsy - Saudi Arabia.

\section{Introduction}

EPILEPSY is a common neurological condition associated with recurrent seizures. Approximately 50 million people worldwide have epilepsy, and nearly $80 \%$ of them live in developing regions [1-4].

The reported annual incidence rates for epilepsy vary from country to country, being $11 / 100,000 /$ year in Norway, 33/100,000 in Italy, and 48/100,000 in the United Kingdom. It has been observed that the highest incidence rates are found in the populations of developing countries with values of 140-230/ 100,000/year [5]. Data from Arab countries revealed prevalence rates of 0.9/1000 in Sudan, [6] 2.3/1000 in Libya, [7] and 6.5/1000 in Saudi Arabia [8].

Epilepsy has been always surrounded by fear, misunderstanding, social discrimination and stigma 
[9-12]. Being an epileptic child, especially at school children, has major effects on children both academically and psychosocially [13]. Children suffering from epilepsy are often avoided and disliked. They are usually at an increased risk for a number of education-related problems such as educational underachievement, learning disabilities, mental health problems, and social isolation. Sometimes, social attitude and discrimination against children with epilepsy are more devastating and harmful than the disease itself [14]

In general, most teachers do not receive any formal instructions on epilepsy during their education and training, despite the fact that as much as $40 \%$ of the children's developing life is spent at school [15]. Teachers' knowledge toward epilepsy may determine their practices toward management of students with epilepsy [16].

\section{Subjects and Methods}

This study was conducted during the period from December 2017 till April 2018. It followed a cross-sectional design, which included school teachers in Arar City at the Northern Region of Saudi Arabia.

Based on relevant literature, a questionnaire was constructed by the researchers to test teachers' knowledge and practices regarding management of students who had epilepsy. It comprised questions within two parts, i.e., sociodemographic variables, including age group, gender, qualification, experience in teaching, and school type, while the second section assessed the levels of knowledge (10 statements) and practices (10 statements) about epilepsy.

A pilot study was done before conducting the survey that included 30 individuals, (whose data were excluded from the main study). The pilot study aimed to assess clarity of the questionnaire, and the average time needed for data collection.

\section{Data management and statistical analysis:}

Collected data were verified and coded before entering into a personal computer. Each "correct" response regarding knowledge and practice statements was assigned a score of (1), while "incorrect" or "I don't know" responses were assigned a score of (0). Knowledge and practice scores were separately summed up for each participant. Therefore, a range of 0-10 for both total knowledge and total practice scores were obtained. For each participant, the mean \pm SD for knowledge and practice scores were calculated. The Statistical Package for Social Sciences (SPSS Version 23) was used for data entry and analysis. The description of data was done as mean \pm SD for quantitative variables and frequency and percentage for qualitative ones. Unpaired $t$-test and F-test were applied to test the significance of differences between groups. $p$ values less than 0.05 were considered as statistically significant.

\section{Results}

A total of 404 school teachers participated in this study. Personal characteristics of participant schoolteachers are presented in (Table 1). Almost two thirds of them $(60.9 \%)$ aged $30-50$ years, while $12.1 \%$ aged $<30$ years and $27 \%$ aged $>50$ years. More than three-fourths of participants $(79.2 \%)$ were males. About three-fourths of participants had a Bachelor Degree, while $14.6 \%$ had Diploma and $9.7 \%$ had Master Degree. About one third of participants $(30.2 \%)$ had less than 5 years' experience in teaching, while $23.8 \%$ had 5-10 years' experience and $43 \%$ had more than 10 years' experience. Most participants were in teaching in governmental schools $(88.4 \%$ ), while $11.6 \%$ were teachers in private schools.

Table (2) shows, regarding teachers' knowledge about epilepsy, almost all of them (99\%) stated that they know what epilepsy is, while only $39.4 \%$ knew that epilepsy is not contagious. Only $46.5 \%$ knew causes of epilepsy, while only $30.4 \%$ denied the relation between epilepsy and evil eyes, and $50.5 \%$ correctly responded to questions related to role of certain types of food as triggering factors related to epileptic seizures. Most participants $(83.4 \%)$ correctly stated the relation between epilepsy and increased brain electric charges, while only $44.3 \%$ stated the early symptoms/signs of an imminent epileptic seizure. Only $15.6 \%$ of participants denied that epilepsy does not affect child's intelligence, $67.3 \%$ knew complications of epilepsy, while $38.9 \%$ knew treatment of epilepsy. Participants' mean total knowledge score (out of 10) was $5.15 \pm 1.32$.

Table (3) shows that relatives and friends constitute the main source of teachers' knowledge about epilepsy $(49.1 \%)$, followed by internet $(44.1 \%)$ and lastly mass media (4.9\%), and books $(1.9 \%)$.

Table (4) shows that $75.5 \%$ of participant teachers witnessed epileptic schoolchildren while in seizure. Their practices were mainly to call an ambulance $(72 \%)$, remove any dangerous objects around the victim $(69.1 \%)$, put a soft object between his teeth $(68.6 \%)$, ensure good ventilation $(63.4 \%)$ 
and pull his tongue out (50.5\%). Participants' mean total practice score (out of 10 ) was $4.85 \pm 1.28$.

Table (5) shows that mean teachers' knowledge and practice scores were highest among those aged $>50$ years $(5.34 \pm 1.75$ and $5.20 \pm 1.63$, respectively). However, differences were statistically significantly only regarding practice scores $(p<0.001)$. Female teachers' knowledge and practice scores were higher than those of male teachers, with statistically significant difference only regarding practice scores $(p=0.003)$. Teachers' knowledge and practice scores were highest among those with Master Degree, but with significant difference only regarding their practice $(p=0.029)$. Moreover, knowledge and practice scores did not differ significantly according to teachers' type of school.

Table (1): Personal characteristics of the participant teachers $(n=404)$.

\begin{tabular}{ll}
\hline Characteristics & No. $(\%)$ \\
\hline Age (in years): & $49(12.1 \%)$ \\
$<30$ & $246(60.9 \%)$ \\
$30-50$ & $109(27 \%)$ \\
$>50$ & \\
Gender: & $320(79.2 \%)$ \\
Male & $84(20.8 \%)$ \\
Female & \\
Qualifications: & $306(75.7 \%)$ \\
Bachelor & $59(14.6 \%)$ \\
Diploma & $39(9.7 \%)$ \\
Master & \\
Experience in teaching: & $122(30.2 \%)$ \\
$\quad$ 5 years & $96(23.8 \%)$ \\
5-10 years & $186(43 \%)$ \\
$>10$ years & \\
Type of school: & $47(11.6 \%)$ \\
Private & $357(88.4 \%)$ \\
Public &
\end{tabular}

Table (2): Teachers' correct responses regarding knowledge about epilepsy.

\begin{tabular}{ll}
\hline Knowledge items & No. (\%) \\
\hline - Do you know what is epilepsy? & $400(99.0 \%)$ \\
- Is epilepsy contagious? & $159(39.4 \%)$ \\
- What are the main causes of epilepsy? & $188(46.5 \%)$ \\
- Do spirits and evil eyes cause epilepsy? & $123(30.4 \%)$ \\
- Do some foods trigger epileptic seizure? & $204(50.5 \%)$ \\
- Is epilepsy related to increased brain electric & $373(83.4 \%)$ \\
charges? & \\
- Early symptoms/signs of an imminent epi- & $179(44.3 \%)$ \\
- Deptic seizure & $63(15.6 \%)$ \\
- Coes epilepsy affect child's intelligence? & $272(67.3 \%)$ \\
- Treatment of epilepsy & $157(38.9 \%)$ \\
\hline Total knowledge score (mean \pm SD) & $5.15 \pm 1.32$ \\
\hline
\end{tabular}

Table (3): Teachers' main source of knowledge about epilepsy.

\begin{tabular}{lll}
\hline $\begin{array}{l}\text { Teachers' main source of } \\
\text { knowledge about epilepsy }\end{array}$ & No. & $\%$ \\
\hline Relatives and friends & 100 & 49.1 \\
Internet & 90 & 44.1 \\
Mass media & 10 & 4.9 \\
Books & 4 & 1.9 \\
\hline
\end{tabular}

Table (4): Teachers' practices regarding management of epileptic children at school.

\begin{tabular}{ll}
\hline Teachers' practices & No. (\%) \\
\hline
\end{tabular}

Have you ever seen an epileptic schoolchild 305 (75.5\%) during seizures?

What did you do to the epileptic child?

- Pull his tongue out.

- Remove any dangerous objects around the 279 (69.1\%) child.

- Ensure good ventilation to the child. $256(63.4 \%)$

- Put a soft object between his teeth. $277(68.6 \%)$

- Call an ambulance and send the child to the 291 (72.0\%) hospital.

- Call his parents. $140(34.7 \%)$

- Help the child to lie on his back on the $166(41.1 \%)$ ground.

- Put the child in a dark room and wait till the $49(12.1 \%)$ attack ends.

- Unbutton his shirt around the neck and chest. 108 (26.7\%) - Protect the child from harming himself. $\quad 187$ (46.3\%)

\begin{tabular}{ll}
\hline Total practice score $($ mean \pm SD) & $4.85 \pm 1.28$ \\
\hline
\end{tabular}

Table (5): Teachers' knowledge and practice scores (mean \pm SD) regarding epilepsy.

\begin{tabular}{|c|c|c|c|}
\hline Characteristics & No. & $\begin{array}{c}\text { Knowledge } \\
\text { scores }\end{array}$ & $\begin{array}{l}\text { Practice } \\
\text { scores }\end{array}$ \\
\hline \multicolumn{4}{|l|}{ Age (in years): } \\
\hline$<30$ & 49 & $4.86 \pm 1.42$ & $3.77 \pm 1.05$ \\
\hline $30-49$ & 246 & $5.12 \pm 1.61$ & $4.91 \pm 1.22$ \\
\hline$>50$ & 109 & $5.34 \pm 1.75$ & $5.20 \pm 1.63$ \\
\hline$p$-value & & 0.211 & $<0.001$ \\
\hline \multicolumn{4}{|l|}{ Gender: } \\
\hline Male & 320 & $5.10 \pm 1.31$ & $4.74 \pm 1.44$ \\
\hline Female & 84 & $5.34 \pm 1.47$ & $5.27 \pm 1.53$ \\
\hline$p$-value & & 0.146 & 0.003 \\
\hline \multicolumn{4}{|l|}{ Qualification: } \\
\hline Bachelor & 306 & $5.13 \pm 1.38$ & $4.82 \pm 1.45$ \\
\hline Diploma & 59 & $5.14 \pm 1.46$ & $4.93 \pm 1.59$ \\
\hline Master & 39 & $5.32 \pm 1.62$ & $4.96 \pm 1.77$ \\
\hline$p$-value & & 0.73 & 0.780 \\
\hline \multicolumn{4}{|c|}{ Experience in teaching: } \\
\hline $0-5$ years & 122 & $4.93 \pm 1.80$ & $4.61 \pm 1.33$ \\
\hline $6-10$ years & 96 & $5.05 \pm 1.79$ & $4.79 \pm 1.39$ \\
\hline$>10$ years & 186 & $5.34 \pm 1.85$ & $5.04 \pm 1.46$ \\
\hline$p$-value & & 0.130 & 0.029 \\
\hline \multicolumn{4}{|l|}{ Type of school: } \\
\hline Private & 47 & $5.12 \pm 2.10$ & $4.79 \pm 1.94$ \\
\hline Governmental & 357 & $5.15 \pm 1.63$ & $4.86 \pm 1.51$ \\
\hline$p$-value & & 0.909 & 0.773 \\
\hline
\end{tabular}




\section{Discussion}

Results of this study revealed that $75.5 \%$ of participant teachers witnessed epileptic schoolchildren while in seizure. Nevertheless, teachers' knowledge and practice regarding management of epileptic children were quite low. The mean knowledge score of teachers (out of 10 ) was $5.15 \pm 1.32$, while the mean practice score of teachers (out of 10) was $4.85 \pm 1.28$. Teachers' relatives and friends constituted the main sources of their knowledge about epilepsy, followed by the internet and lastly mass media and books.

These findings are in accordance with those reported by several studies in Saudi Arabia. AlQahtani [17], in Khamis Mushait, reported that $72.7 \%$ of teachers witnessed schoolchildren with epileptic fits. Only one third of teachers were able to provide first aid to students with epileptic seizures. Alhazzani et al., [18] in Aseer Region, Alaqeel and Sabbagh in Riyadh City [19] and Zubaidi et al., [20] in Jeddah City found low levels of participants' knowledge and practices regarding epilepsy management and their main sources for knowledge about epilepsy were friends or relatives. Also in Jeddah, Abulhamail et al., [21] reported that only $17 \%$ of the teachers were well informed about epilepsy. The main sources of knowledge were their friends and relatives as well as the mass media.

Most participant teachers in the present study had some misbeliefs related to epilepsy. For example, it has been revealed that only $15.6 \%$ denied the link between epilepsy and low intelligence, while only $30.4 \%$ denied the relation between epilepsy and evil eye.

Similarly, in Jeddah, Saudi Arabia, Abulhamail et al., [21] stated that although most teachers were highly educated and quite experienced, $27 \%$ continued to believe that spirit possession or evil eye are causes of epilepsy. Ullah and Nabi [22] reported that the misbelief of considering epilepsy as a supernatural possession was blamed by $16 \%$ of teachers, while in India Thacker et al., [23] reported that $5.5 \%$ of participant teachers believed that epilepsy is caused by evil spirits.

Ullah and Nabi [22] noted that myths and misbeliefs pass down generation after generation and give rise to misconceptions, such as linking mental retardation with epilepsy. This link varied among different developing countries, e.g., 23.6\%, in Vietnam [24], 16\% in China [25] and 7\% in Taiwan [26]

Our results showed that teachers' knowledge and practice scores were highest among teachers who were $>50$ years old, females, those who had Master degree, those with $>10$ years' experience in teaching, and those who work at governmental schools. However, teachers' knowledge did not differ significantly according to their personal characteristics. However, teachers' knowledge scores did not differ significantly according to their personal characteristics, while teachers' practice scores differed significantly only according to their age, gender and experience in teaching ( $p<0.001,0.003$ and 0.029 , respectively).

These findings are in accordance with those of Bekiroglu et al., [27], which concluded that with higher qualifications and education levels, knowledge about epilepsy improves in the society. Moreover, Zubaidi et al., [20], in Jeddah City, Saudi Arabia, reported that teachers' knowledge mean score about epilepsy (5 out of 13) was significantly higher among senior teachers and those with longer years of experience in teaching. Moreover, Alkhamra et al., [14] in Jordan, reported that teachers with higher educational levels and higher ranks showed more better knowledge and practices regarding epilepsy management. Brabcova et al., [28] observed that as the number of years working as a teacher increased, practice scores regarding management of epilepsy increased. In Pakistan, Ullah and Nabi [22] reported that most teachers, especially at private schools, have low knowledge regarding epilepsy.

Teachers' higher knowledge and significantly better practices among older teachers (aged $>50$ years) may be due to their gained experience that accumulated through dealing with schoolchildren. Moreover, the finding that female teachers' higher knowledgeable and significantly better practice than male teachers may be related to the female's natural better interest and skill toward care of children.

In conclusion, teachers in Northern Saudi Arabia have poor knowledge and practice about management of epilepsy among schoolchildren. Therefore, it is recommended to raise teachers' knowledge and skills regarding proper handling of schoolchildren with seizures in the educational setting. The school health programs should focus on the development and implementation of epilepsy education programs.

\section{References}

1- ALMUTAIRI A.M., ANSARI T., SAMI W. and BAZ S.: Public knowledge and attitudes toward epilepsy in Majmaah. Journal of neurosciences in rural practice, Oct., 7 (4): 499, 2016. 
2- AL-RAJEH S., AWADA A., BADEMOSI O. and OGUNNIYI A.: The prevalence of epilepsy and other seizure disorders in an Arab population: A community-based study. Seizure-European Journal of Epilepsy, Sep. 1, 10 (6): 410-4, 2010.

3- WHO. Fact Sheet No. 999. Available at: http://www.who. int/mediacentre/factsheets/ fs999/en.

4- AL-KHATEEB J.M. and AL-KHATEEB A.J.: Research on psychosocial aspects of epilepsy in Arab countries: A review of literature. Epilepsy \& Behavior, Feb. 1., 31: 256-62, 2014

5- NGUGI A.K., BOTTOMLEY C., KLEINSCHMIDT I., SANDER J.W. and NEWTON C.R.: Estimation of the burden of active and life-time epilepsy: A meta-analytic approach. Epilepsia. May, 51 (5): 883-90, 2010.

6- MOHAMMED I.N. and BABIKIR H.E.: Traditional and spiritual medicine among Sudanese children with epilepsy. Sudanese Journal of Paediatrics, 13 (1): 31, 2013.

7- BENAMER H.T. and GROSSET D.G.: A systematic review of the epidemiology of epilepsy in Arab countries. Epilepsia. Oct., 50 (10): 2301-4, 2009.

8- AL-RAJEH S., AWADA A., BADEMOSI O. and OGUNNIYI A.: The prevalence of epilepsy and other seizure disorders in an Arab population: A community-based study. Seizure-European Journal of Epilepsy, Sep. 1, 10 (6): 410-4, 2010.

9- ASATO M.R., DOSS J.L. and PLIOPLYS S.: Clinicfriendly screening for cognitive and mental health problems in school-aged youth with epilepsy. Epilepsy \& Behavior, Jul. 1, 48: 97-102, 2015.

10- SZEMERE E. and JOKEIT H.: Quality of life is socialTowards an improvement of social abilities in patients with epilepsy. Seizure, Mar. 1, 26: 12-21, 2015.

11- HUN C., HOK T., ROS S., CHAN S. and BHALLA D.: Epilepsy: Some controversies, some knowledge and some experience from Cambodia. Neurology India. Nov. 1, 62 (6): 606, 2014.

12- ENGLAND M.J., LIVERMAN C.T., SCHULTZ A.M. and STRAWBRIDGE L.M.: Epilepsy across the spectrum: Promoting health and understanding: A summary of the Institute of Medicine report. Epilepsy \& Behavior. Oct. 1, 25 (2): 266-76, 2012.

13- BABIKAR H.E. and ABBAS I.M.: Knowledge, practice and attitude toward epilepsy among primary and secondary school teachers in South Gezira locality, Gezira State, Sudan. Journal of Family and Community Medicine, Jan, 18 (1): 17, 2011.

14- ALKHAMRA H., TANNOUS A., HADIDI M. and ALKHATEEB J.: Knowledge and attitudes toward epilepsy among school teachers and counselors in Jordan. Epilepsy \& Behavior, Aug. 1, 24 (4): 430-4, 2012.

15- DANTAS F.G., CARIRI G.A., CARIRI G.A. and RIBEIRO FILHO A.R.: Knowledge and attitudes toward epilepsy among primary, secondary and tertiary level teachers. Arquivos De Neuro-Psiquiatria. Sep., 59 (3B): 712-6, 2001.

16- AL-HASHEMI E. , ASHKANANI A., AL-QATTAN H.,
MAHMOUD A., AL-KABBANI M., AL-JUHAIDLI A., JAAFAR A. and AL-HASHEMI Z.: Knowledge about epilepsy and attitudes toward students with epilepsy among middle and high school teachers in Kuwait. International Journal of Pediatrics, 2016.

17- ALQAHTANI J.M.: Knowledge and practice of schoolteachers towards students with epilepsy in Khamis Mushate, Southern Saudi Arabia. J. Family Community Med., 22 (3): 163-8, 2015.

18-ALHAZZANI A.A., ALQAHTANI A.M. ABOUELYAZID A., ALQAHTANI A.M., ALQAHTANI N.A., ASIRI K.M., MUHAYA A.A. and ALAMRI H.A.: Public awareness, knowledge, and attitudes toward epilepsy in the Aseer region, Saudi Arabia-A communitybased cross-sectional study. Epilepsy \& Behavior, 63: 636, 2016.

19- ALAQEEL A. and SABBAGH A.J.: Epilepsy; What do Saudi's living in Riyadh know? Seizure, 22 (3): 205-9, 2013.

20- ZUBAIDI A., ABDULLAH M., ALSUDAIRY N.M., ALZUBAIDI B.A., JOHARJI R., ALQURASHI S.M., ALSADI K. and ABULELA A.A.: Assessment of Knowledge and Attitude and Practice of Parents towards Epilepsy among Children in Jeddah City. Egyptian Journal of Hospital Medicine, 69: 6, 2017.

2 1- ABULHAMAIL A. S., AL-SULAMI F.E., ALNOURI M.A., MAHROUS N.M., JOHARJI D.G., ALBOGAMI M.M., et al.: Primary school teacher's knowledge and attitudes toward children with epilepsy. Seizure, 23: 2803, 2014.

22- ULLAH S. and NABI G.: Knowledge, Attitude and Practices of School Teachers towards Epileptic School Students at District Dir Lower, Khyber Pakhtunkhwa, Pakistan. International Journal of Neuroscience and Behavioral Science, 3 (1): 1-6, 2015.

23- THACKER A.K., VERMA A.M., JI R., THACKER P. and MISHRA P.: Knowledge awareness and attitude about epilepsy among schoolteachers in India. Seizure, 17: 8: 684-90, 2008

24- LE Q.C., DINH D.T. and JALLON P.: Survey of public awareness, attitudes and understanding toward epilepsy in Nhan Chinh, Hanoi, Vietnam, in 2003. Epilepsy Behaviour, 8 (1): 176-80, 2006.

25- LAI C.W., HWANG X.S., LAI Y.H., ZHANG Z.Q., LIU G.J. and YANG M.Z.: Survey of public awareness, understanding and attitudes toward epilepsy in Henan Province, China. Epilepsia, 31 (2): 182-7, 1990.

26- CHUNG M.Y., CHANG Y.C., LAI Y.H. and LAI C.W.: Survey of public awareness, understanding and attitudes toward epilepsy in Taiwan. Epilepsia, 36, 5: 488-93, 1995.

27- BEKIROGLU N., OZKAN R., GURSES C., ARPAC1 B. and DERVENT A.: A study on awareness and attitude of teachers on epilepsy in Istanbul. Seizure, 13 (7): 517-22, 2004.

28- BRABCOVA D., LOVASOVA V., KOHOUT J. and ZARUBOVA J.: Familiarity with and attitudes towards epilepsy among teachers at Czech elementary schoolsthe effect of personal experience and subspecialization. Seizure, 21 (6): 461-5, 2012. 


\section{مستوى معرفة وممارسات المعلمين

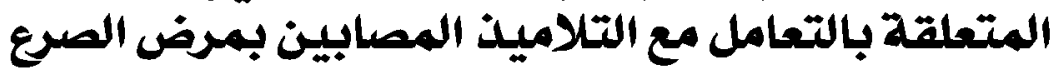

هدف البحث: تقييم معرفة المعلمين وممارستهم فيما يتعلق بالتعامل مع مرض الصرع لدى آطفال المدارس.

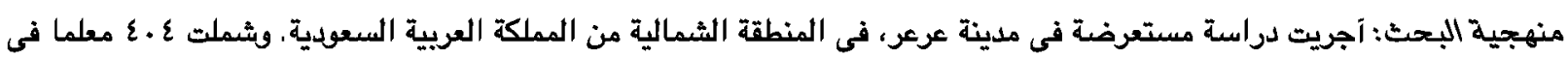
المدارس (·rr من الذكود وع من الإناث). وقد تم تصميم إستبيان لقياس معرفة وممارسة المعلمين حمل التعامل مع التلاميذ المصابين

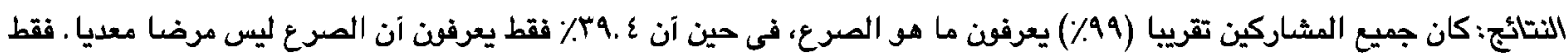

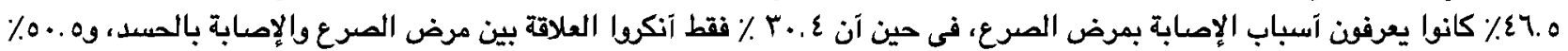

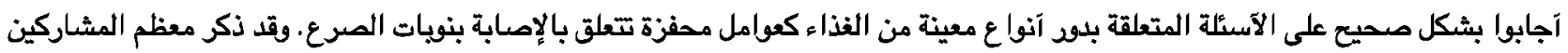

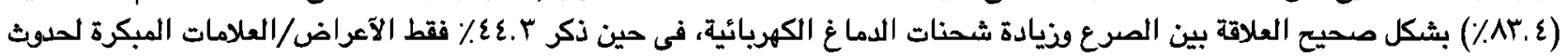

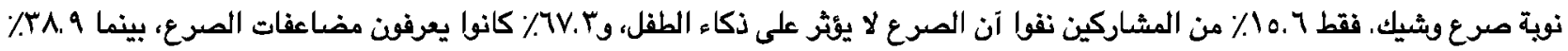

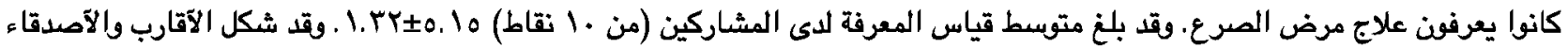

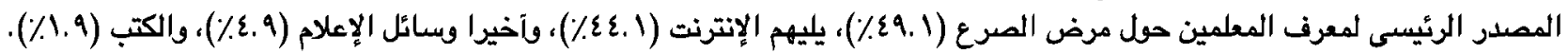

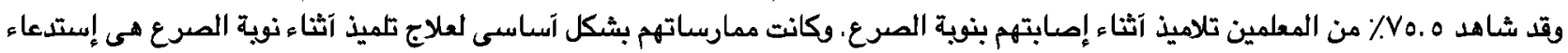

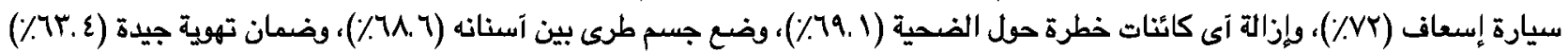

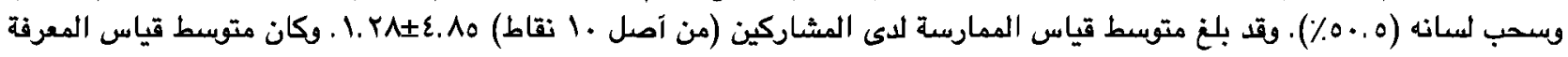

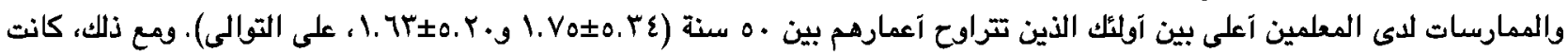

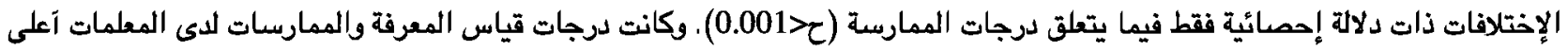

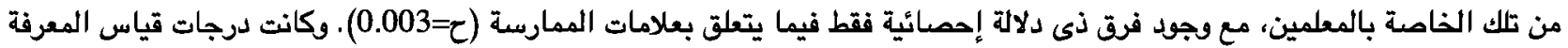

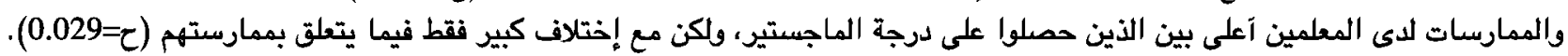

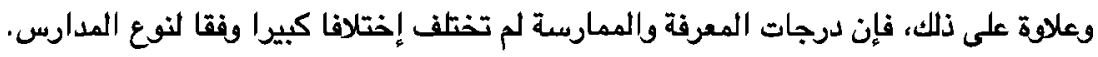

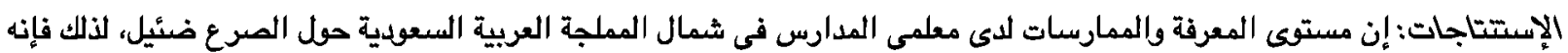

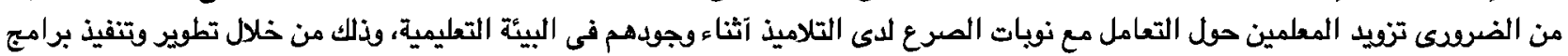
تثقيفية حوال الصرع. 